\title{
Faktor yang Berhubungan dengan Kejadian Tinea Pedis pada Mahasiswa Tamta di Resimen Induk Kodam VII Wirabuana Makassar
}

\author{
Santriani Hadi ${ }^{*}$ \\ 'Parasitologi, Fakultas Kedokteran, Unversitas Muslim Indonesia, Makassar, Indonesia \\ *Email Korespondensi: santrianidewa@gmail.com Telp: 082271111694
}

\begin{abstract}
ABSTRAK
Latar belakang: Tinea pedis merupakan penyakit urutan pertama dari 10 penyakit terbesar di Poliklinik Resimen Induk Kodam VII Wirabuana Makassar 2015, beban latihan siswa Tamtama yang cukup lama menggunakan sepatu setiap harinya dan juga sengatan matahari dapat menyebabkan gangguan kesehatan termasuk infeksi kulit, serta kondisi lingkungan latihan siswa Tamtama Makassar yang panas dan lembab dapat menimbulkan produksi keringat berlebih, termasuk di daerah sekitar kaki. Penelitian ini dilakukan bertujuan untuk menganalisa faktor yang berpengaruh terhadap kejadian Tinea Pedis di Resimen Induk Kodam VII Wirabuana Makassar.

Metode: Penelitian ini merupakan penelitian observasional analitik dengan pendekatan cross sectional. Populasi dan sampel adalah seluruh siswa Tamtama yang memenuhi karakteristik yang berjumlah 225 orang dan sampel digunakan dalam penelitian ini sebanyak 60 siswa tamtama. Data dikumpulkan dengan wawancara menggunakan kuesioner. Komponen kuesioner meliputi kebersihan kulit dan kebersihan kaki.

Hasil: Hasil Penelitian ini menunjukkan bahwa setelah dilakukan uji statistik didapatkan bahwa kebersihan kulit $(\mathrm{p}=0.000)$ merupakan faktor yang berhubungan dengan kejadian Tinea Pedis, kebersihan handuk $(\mathrm{p}=0.002)$ merupakan faktor yang berhubungan terhadap kejadian Tinea Pedis.
\end{abstract}

Kesimpulan: Faktor-faktor yang berhubungan dengan Tinea Pedis adalah kebersihan kulit dan kebersihan handuk.

Kata kunci: Tinea Pedis; infeksi kulit; kebersihan

Article history:

Received: 1 May 2020

Accepted: 23 June 2020

Publish Online: 30 June 2020

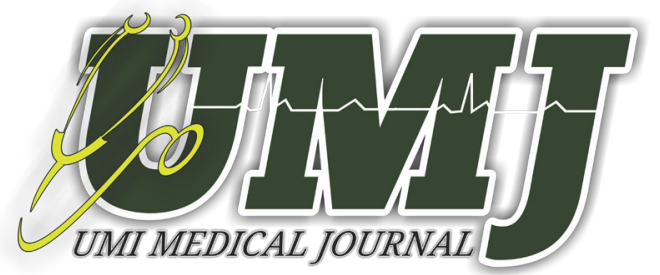

Published By :

Fakultas Kedokteran

Universitas Muslim Indonesia

Phone:

+6282293330302
Address:

Jl. Urip Sumoharjo Km. 5 (Kampus II UMI)

Makassar, Sulawesi Selatan.

Email:

medicaljournal@umi.ac.id 


\section{ABSTRACT}

Background: Tinea pedis is the first of the 10 biggest diseases in the 2015 Kodam VII Wirabuana Main Regiment Polyclinic, the training load of Tamtama students who use shoes for a long time and can also be adjusted by the Makassar Tamtama students which can cause heat and humidity, excessive sweating, including in the area around the foot. This research was conducted to test, analyze the factors that oppose the Tinea Pedis incident at the Wiramuana Makassar Kodam VII Main Regiment.

Method: This research was an observational analytic study using cross sectional study. The population and sample are all Tamtama students who meet the characteristics collected 225 people and the sample used in this study were 60 enlisted students. Data were collected by interview using a questionnaire. Components of the questionnaire include skin hygiene and foot hygiene.

Results: The results of this study showed that after statistical tests obtained from skin hygiene $(\mathrm{p}=0.000)$ were factors related to the occurrence of Tinea Pedis, towel hygiene $(\mathrm{p}=0.002)$ was a factor related to Tinea Pedis occurrence. Conclusion: Factors related to Tinea Pedis are skin cleanliness and towel cleanliness.

Keywords: Tinea Pedis; skin infection; cleanliness

\section{PENDAHULUAN}

Kulit merupakan pembungkus yang elastis yang melindungi tubuh dari pengaruh lingkungan. Kulit sebagai organ yang berfungsi sebagai proteksi, memegang peranan penting dalam meminimalkan setiap gangguan dan ancaman yang masuk melewati kulit ${ }^{1}$. Salah satunya adalah infeksi kulit pada sela jari kaki dan telapak kaki yang disebabkan oleh jamur atau yang lebih dikenal sebagai Tinea pedis atau ringworm of the foof. Tinea pedis disebabkan oleh Trichophyton rubrum yang sering memberikan kelainan menahun. Tinea pedis sering menyerang orang dewasa yang bekerja ditempat basah seperti tukang cuci, petani atau orang yang setiap harinya memakai sepatu tertutup misalnya tentara ${ }^{2}$.

Tinea pedis atau ringworm of the foot adalah infeksi dermatofita pada kaki, terutama pada sela jari dan telapak kaki. Tinea pedis merupakan infeksi jamur yang paling sering terjadi. Penyebabnya yang paling sering adalah Trichophyton rubrum yang memberikan kelainan menahun. Paling banyak ditemukan diantara jari ke-4 dan ke-5, dan seringkali meluas ke bawah jari dan sela jari-jari lain, sering pula terlihat maserasi berupa kulit putih dan rapuh. Jika bagian kulit yang mati ini dibersihkan, maka akan terlihat kulit baru, yang pada umumnya juga telah diserang jamur. Jamur tumbuh pada kulit kaki karena faktor kelembaban, hal itu dapat disebabkan kaki yang sering berkeringat, kaos kaki kurang dijaga kebersihannya, atau sepatu terlalu tertutup. Jari-jari kaki sangat rentan terinfeksi jamur Tinea pedis, terutama pada orang yang sering memakai sepatu tertutup pada kesehariannya. 
Siswa Tamtama yang bekerja dari pagi hingga sore memakai alat pelindung diri yaitu sepatu untuk melindungi kaki mereka dari paparan sampah. Mereka juga memakai kaos kaki ketika bekerja. Pemakaian sepatu tertutup dan kaos kaki dalam jangka waktu yang lama dapat menyebabkan kulit di sekitar kaki lembab karena keringat, dimana kondisi kulit yang lembab dapat menjadi media yang baik untuk jamur tumbuh dengan subur ${ }^{3}$.

Beban latihan siswa Tamtama yang cukup lama menggunakan sepatu setiap harinya dan juga sengatan matahari dapat menyebabkan gangguan kesehatan termasuk infeksi kulit. Lingkungan tempat tinggal siswa tamtama yang tidak bersih dapat menjadi perantara kontak dengan jamur penyebab Tinea pedis sehingga infeksi jamur dapat ditularkan baik secara langsung maupun tidak langsung. Kondisi lingkungan latihan siswa Tamtama Makasar yang panas dan lembab dapat menimbulkan produksi keringat berlebih, termasuk di daerah sekitar kaki. Kondisi inilah yang dapat memicu jamur tumbuh dengan subur. Penelitian lain tentang angka kejadian Tinea pedis juga pernah dilakukan pada anggota Brimob Semarang. Pada penelitian tersebut ditemukan angka kejadian Tinea pedis sebesar 24,35\%. Pemakaian sepatu tertutup dalam waktu yang lama oleh anggota Brimob dan pemulung ketika bekerja dapat menyebabkan kulit di sekitar jari kaki menjadi lembab karena produksi keringat berlebih. Hal inilah yang menjadi faktor risiko jamur tumbuh khususnya jamur penyebab Tinea pedis ${ }^{4}$.

Higiene dan sanitasi yang buruk masih merupakan masalah kesehatan terbesar di negara berkembang. Menurut WHO, air yang tidak bersih, sanitasi yang buruk, dan higiene yang tidak baik adalah penyebab kematian utama dan penyebab penyakit kulit terbanyak kedua di negara berkembang. Meningkatkan higiene dan sanitasi adalah langkah paling penting untuk meningkatkan kesehatan anak dan prioritas utama dalam promosi kesehatan untuk negara berkembang 5 .

Kurangnya air bersih khususnya untuk menjaga kebersihan diri, dapat menimbulkan berbagai penyakit kulit dan mata. Hal ini terjadi karena bakteri yang selalu ada pada kulit dan mata mempunyai kesempatan untuk berkembang. Apalagi diantara masyarakat dengan keadaan gizi yang kurang seperti kekurangan vitamin A, B, dan C. Penyakit akibat kurangnya air bersih adalah penyakit trachoma dan segala macam penyakit kulit yang disebabkan jamur dan bakteri ${ }^{6}$.

\section{METODE}

Desain studi penelitian ini adalah cross sectional. Populasi dalam penelitian ini adalah seluruh siswa Tamtama yang memenuhi karakteristik yang berjumlah 225 orang. Penelitian ini dilakukan di Resimen Induk Kodam VII Wirabuana Makassar yang terletak di Kelurahan Manggala, Kecamatan Manggala. Pelaksanaan penelitian dimulai pada bulan Februari 2016.

Sampel yang digunakan dalam penelitian ini sebanyak 60 siswa Tamtama. Analisis data menggunakan dua cara yaitu analisis univariat yang dilakukan pada setiap variabel untuk deskripsi data dan analisis bivariat yang dilakukan terhadap lebih dari dua kelompok yang diduga berhubungan dengan analisis uji Chi-Square. 


\section{HASIL}

\section{Distribusi Karakter Responden}

Tabel 1.1 Tabel Distribusi Berdasarkan Karakteristik Responden

\begin{tabular}{ccc}
\hline Karakteristik Responden & \multicolumn{2}{c}{ Total } \\
\cline { 2 - 3 } & $\mathbf{n}$ & \% \\
\hline Umur (Tahun) & 37 & 61.7 \\
19 & 19 & 31.7 \\
20 & 21 & 6.7 \\
21 & 60 & 100.0 \\
Jumlah & & \\
Kelas & 20 & 33.3 \\
A & 19 & 31.7 \\
B & 21 & 35.0 \\
C & 60 & 100.0 \\
\hline Jumlah & &
\end{tabular}

Tabel 1.1 Menunjukkan bahwa pada jumlah responden dengan umur paling sedikit yaitu umur 21 tahun sebanyak 21 orang (6.7\%) dan paling banyak yaitu umur 19 tahun sebanyak 37 orang (61.7). Jumlah responden sebanyak 21 orang (35.0\%) dan yang paling sedikit yaitu kelas B sebanyak 19 orang $(31.7 \%)$.

\section{Distribusi Variabel Yang Diteliti}

a) Distribusi Variabel Personal Hygiene

Tabel 1.2 Distribusi Kejadian KOH, Kebersihan Kulit, Kebersihan Tangan dan Kuku, Kebersihan Kaki

\begin{tabular}{ccc}
\hline \multirow{2}{*}{ Variabel Yang Diteliti } & \multicolumn{2}{c}{ Total } \\
\cline { 2 - 3 } & $\mathbf{N}$ & \% \\
\hline Kejadian KOH & 36 & 60.0 \\
Positif & 24 & 40.0 \\
Negatif & 60 & 100.0 \\
Jumlah & & \\
Kebersihan Kulit & 29 & 48.3 \\
Baik & 31 & 51.7 \\
Buruk & 60 & 100.0 \\
Jumlah & & 35.0 \\
Kebersihan Kaki & 21 & 65.0 \\
Baik & 39 & 100.0 \\
Buruk & 60 & \\
Jumlah &
\end{tabular}


Tabel 1.2 menunjukkan bahwa responden positif Tinea Pedis berdasarkan pemeriksaan KOH yaitu 36 orang (60.0\%) sedangkan yang negatif menderita Tinea Pedis sebanyak 24 orang (40.0\%). Responden yang menjaga kebersihan kulitnya lebih sedikit yaitu 29 orang (48.3\%) dibanding dengan reponden yang tidak menjaga kebersihan kulitnya yaitu sebanyak 31 orang (51.7\%). Responden yang menjaga kebersihan tangan dan kukunya lebih banyak yaitu 43 orang $(71.7 \%)$ dibanding dengan reponden yang tidak menjaga kebersihan tangan dan kukunya yaitu sebanyak 17 orang (28.3\%). Tabel 1.2 juga menunjukkan bahwa responden yang menjaga kebersihan kakinya lebih sedikit yaitu 21 orang (35.0\%) dibandingkan dengan responden yang tidak menjaga kebersihan kakinya yaitu 39 orang $(65.0 \%)$.

\section{Hasil Analisis Variabel Penelitian}

Kebersihan kulit, tangan dan kuku serta kebersihan kaki dapat dilihat pada statistik sebagai berikut:

\section{Hubungan kebersihan kulit terhadap kejadian Tinea Pedis}

Kebersihan kulit merupakan salah satu indikator kesehatan. Kebersihan kulit yang baik akan mempengaruhi kejadian Tinea Pedis. Hubungan antara kebersihan kulit terhadap kejadian Tinea pedis dapat dilihat pada tabel berikut:

Tabel 1.3 Distribusi Hubungan Kebersihan kulit terhadap Kejadian Tinea pedis di Resimen Induk KODAM VII Wirabuana Kota Makassar Tahun 2016

\begin{tabular}{|c|c|c|c|c|c|c|c|}
\hline \multirow{3}{*}{ Kebersihan Kulit } & \multicolumn{4}{|c|}{ Kejadian Tinea pedis } & & & \multirow{3}{*}{$P$} \\
\hline & \multicolumn{2}{|c|}{ Positif } & \multicolumn{2}{|c|}{ Negatif } & \multicolumn{2}{|c|}{ Total } & \\
\hline & $\mathrm{N}$ & $\%$ & $\mathrm{~N}$ & $\%$ & $\mathrm{~N}$ & $\%$ & \\
\hline Baik & 10 & 34.5 & 19 & 65.5 & 29 & 100.0 & \\
\hline Buruk & 26 & 83.9 & 5 & 16.1 & 31 & 100.0 & 0.000 \\
\hline Jumlah & 36 & 60.0 & 24 & 40.0 & 60 & 100.0 & \\
\hline
\end{tabular}

Sumber: Data Primer 2016

Berdasarkan uji Chi Square diperoleh nilai $\mathrm{p}=0.000(<0.05)$ yang berarti ada hubungan antara kebersihan kulit dengan kejadian Tinea pedis di Resimen Induk KODAM VII Wirabuana Makassar

\section{Hubungan kebersihan kaki terhadap kejadian Tinea Pedis}

Kebersihan kaki merupakan salah satu indikator kesehatan. Kebersihan kaki yang baik akan mempengaruhi kejadian Tinea pedis. Hubungan antara kebersihan Tinea pedis terhadap kejadian skabies dapat dilihat pada tabel berikut: 
Tabel 1.4 Distribusi Hubungan Kebersihan Kaki dengan Kejadian Tinea pedis di Resimen Induk KODAM VII Wirabuana Kota Makassar Tahun 2016

\begin{tabular}{|c|c|c|c|c|c|c|c|}
\hline \multirow{3}{*}{ Kebersihan Kaki } & \multicolumn{4}{|c|}{ Kejadian Tinea Pedis } & & & \multirow{3}{*}{$\boldsymbol{P}$} \\
\hline & \multicolumn{2}{|c|}{ Positif } & \multicolumn{2}{|c|}{ Negatif } & \multicolumn{2}{|c|}{ Total } & \\
\hline & $\mathrm{N}$ & $\%$ & $\mathrm{~N}$ & $\%$ & $\mathrm{~N}$ & $\%$ & \\
\hline Baik & 7 & 33.3 & 14 & 66.7 & 31 & 100.0 & \\
\hline Buruk & 29 & 74.4 & 10 & 25.6 & 29 & 100.0 & 0.002 \\
\hline Jumlah & 36 & 60.0 & 24 & 40.0 & 60 & 100.0 & \\
\hline
\end{tabular}

Sumber: Data Primer 2016

Berdasarkan uji Chi Square diperoleh nilai $p=0.002(<0.05)$ yang berarti ada hubungan antara kebersihan handuk dengan kejadian penyakit kulit di Resimen Induk KODAM VII Wirabuana Makassar.

\section{PEMBAHASAN}

Banyak faktor yang dapat menyebabkan Tinea pedis dan salah satunya ialah hygiene perorangan. Kebersihan perorangan adalah suatu tindakan untuk memelihara kebersihan dan kesehatan seseorang untuk kesejahteraan fisik dan psikis ${ }^{7}$. Adapun pembahasan variabel penelitian terhadap kejadian penyakit kulit sebagai berikut:

\section{Hubungan kebersihan kulit terhadap kejadian Tinea Pedis}

Hasil penelitian menunjukkan ada hubungan antara kebersihan kulit dengan kejadian Tinea pedis di Resimen Induk KODAM VII Makassar. Pada penelitian yang dilakukan di TPA Jatibarang didapatkan hasil yang serupa yaitu ada hubungan kebersihan kulit dengan kejadian Tinea pedis pada pemulung ${ }^{8}$. Hal yang serupa juga didapatkan pada mahasiswa kedokteran di Makassar, berdasarkan hasil penelitian ada hubungan signifikan dan bermakna antara personal hygiene (kebersihan kulit, kebersihan tangan dan kuku, kebersihan pakaian, kebersihan handuk, kebersihan tempat tidur dan sprei) dengan kejadian Tinea Pedis ${ }^{9}$.

Meskipun siswa tamtama mandi 1 kali atau 2 kali dalam sehari jika air yang digunakan untuk mandi tidak memenuhi syarat kualitas air bersih maka akan tetap berisiko terkena Tinea pedis. Hal ini dapat disebabkan karena air yang digunakan untuk mandi telah terkontaminasi jamur maupun spora jamur baik melalui udara ataupun aliran leacheate dapat menjadi perantara penularan jamur penyebab Tinea pedis.

Menurut Tarwoto dan Martonah (2012), kebersihan diri termasuk kebersihan kulit sangat penting dalam usaha pemeliharaan kesehatan seperti mandi 2 kali sehari menggunakan sabun agar terhindar dari penyakit menular. Bagi kenyamanan tubuh kita sendiri, mandi 2 kali sehari seharusnya merupakan suatu keharusan ${ }^{10}$. 


\section{Hubungan kebersihan kaki terhadap kejadian Tinea Pedis}

Hasil penelitian menunjukkan ada hubungan antara kebersihan kaki dengan kejadian Tinea pedis dan ini dibuktikan dengan uji chi diperoleh nilai $\mathrm{p}=0.002(<0.05)$. Hal ini dapat disebabkan karena lap atau handuk yang dipakai mengeringkan kaki telah terkontaminasi spora jamur penyebab Tinea pedis. Jadi walaupun dikeringkan, tetapi handuk yang digunakan telah terkontaminasi jamur maka tidak akan dapat mencegah terjadinya Tinea pedis. Hal ini sesuai dengan teori Djajadilaga (2014) bahwa jamur mudah ditularkan dari barang yang melekat pada kaki, seperti pakaian serta kaos kaki yang ditumbuhi jamur. Perkembangan jamur juga sangat dipengaruhi oleh suhu dan kelembaban apalagi dilokasi penelitian yang letaknya di Malino Gowa tersebut dingin dan sangat lembab jadi memudahkan jamur berkembang ${ }^{11}$.

Hal ini sesuai dengan teori Siregar (2010) dan Bramono (2014) bahwa kelembaban dapat menjadi faktor pencetus infeksi jamur ${ }^{12,13}$. Karena kondisi sepatu yang sebagian besar tidak lembab maka kemungkinan jamur penyebab Tinea pedis untuk tumbuh kecil sehingga infeksi jamur tidak terjadi. Hal ini berbeda dengan penelitian yang dilakukan di Pesantren Al-falah bahwa tidak ada hubungan antara kebersihan kaki dengan kejadian penyakit dengan hasil uji statistik $0.170(\mathrm{p}>0,05)^{14}$.

Hasil penelitian serupa didapatkan pada siswa Secata PK gelombang II tahap I Rindam Jaya. Dengan hasil penelitian, terdapat hubungan bermakna antara praktik kebersihan diri dengan angka kejadian Tinea pedis pada siswa Secata PK Gelombang II Tahap I TNI AD Rindam Jaya Condet. Hal ini disebabkan karena peningkatan kelembaban dan pertumbuhan mikroorganisme akibat kebersihan diri yang kurang. Selain itu, ditemukan kelainan kulit lainnya yang dapat mengganggu aktifitas siswa Secata PK Gelombang II Tahap I Rindam Jaya ${ }^{15}$

\section{KESIMPULAN}

Pada penelitian ini didapatkan bahwa ada hubungan siginifikan antara kebersihan kulit dengan kejadian Tinea Pedis di Resimen Induk KODAM VII Wirabuana sedangkan tidak ada hubungan signifikan antara kebersihan kaki dengan kejadian tinea pedis di Resimen Induk KODAM VII Wirabuana. 


\section{DAFTAR PUSTAKA}

1. Harahap M. Ilmu Penyakit Kulit. Jakarta: Hipokrates; 2013

2. Robbins, M. Courtney. Dermatofitosis; 2009.

3. Astono S, Sudarja H. Penyakit Kulit di Kalangan Tenaga Kerja industri Plywood di Propinsi Kalimantan Selatan. Jakarta: FK UI; 2014.

4. Agusni I, Kasansengari US. Gambaran Klinis Penyakit-Penyakit Jamur Superfisialis pada Kulit. Dalam: Kumpulan Naskah Jurnal Dermato-Mikologi. Surabaya: FK UNAIR;2012.

5. Anna N, Windy R, Lita N. Personal Hygiene Siswa Sekolah Dasar Jatinagor. Jurnal Fakultas Ilmu Keperawatan. 2012;1(1):1-14.

6. Slamet, Juli Soemirat. Kesehatan Lingkungan. Cetakan ke 9 edisi Revisi. Yogyakarta: Gadjah Mada University Press;2011.

7. Tarwoto \& Wartonah. Kebutuhan Dasar Manusia dan Proses Keperawatan. Edisi Kelima. Jakarta: SalembaMedika;2014.

8. Ratna D, Suhartono, Yusniar H. Faktor-faktor yang berhubungan dengan kejadian Tinea Pedis Pada Pemulung Di TPA Jatibarang Semarang. Jurnal Kesehatan Lingkungan Indonesia. 2010;5(1):25-28.

9. Nur IBA. Hubungan Personal Hygiene dengan Keluhan Tinea Pedis Pada Mahasiswa Fakultas Kedokteran Universitas Hasanuddin. Jurnal repository Unhas. 2015.

10. Tarwoto \& Wartonah. Kebutuhan Dasar Manusia dan Proses Keperawatan. Edisi Kelima. Jakarta: SalembaMedika; 2014.

11. Djajadilaga, Sandr AWM. 2014. Kaki jangan remehkan dia.

12. Bramono K. Pemaparan tentang jamur. Jakarta: FKUI; 2014.

13. Siregar. Penyakit jamur kulit. Edisi Revisi 2010. Jakarta: EGC; 2010. p.33-34.

14. Gusti YW. 2014. Hubungan Pengetahuan dan Personal Hygiene dengan Kejadian Penyakit Tinea di Pondok Pesantren Al-Falah.

15. Nunik. Hubungan Praktik Kebersihan Diri dengan Tinea pedis pada siswa Secata Prajurit Karir (PK) Gelombang II Tahap I Rindam Jaya. Jurnal Keseharan Universitas Veteran Malang. 2010. 